\title{
PENILAIAN KINERJA GURU TERBAIK PADA SMK PUTRA SATRIA DENGAN MENGGUNAKAN METODE SIMPLE ADDITIVE WEIGHTING (SAW)
}

\author{
Alita Vera Oktavia ${ }^{1)}$, Grace Gata ${ }^{2)}$ \\ ${ }^{1}$ Sistem Informasi, Fakultas Teknologi Informasi, Universitas Budi Luhur \\ ${ }^{1,2} \mathrm{Jl}$. Raya Ciledug, Petukangan Utara, Kebayoran Lama, Jakarta Selatan 12260 \\ E-mail : 1512501303@student.budiluhur.ac.id ${ }^{1)}$, grace.gata@budiluhur.ac.id ${ }^{2)}$
}

\begin{abstract}
Abstrak
Penelitian ini membahas tentang pengambilan keputusan penilaian kinerja guru pada SMK Putra Satria yang bertujuan untuk mempermudahkan dalam proses menghasilkan keputusan dalam penilaian kinerja guru sesuai dengan kriteria pada SMK Putra Satria. Masalah yang terjadi kepala sekolah mengalami kesulitan dalam melakukan rekap hasil evaluasi kinerja guru, sehingga proses pengolahan datanya lama dan sering terjadi kesalahan. Beberapa masalah dalam menentukan penilaian guru terbaik adalah penilaian masih manual dan kurang tepat. Hal ini membuat kepala sekolah sebagai pengambil keputusan sulit menentukan guru yang mempunyai nilai terbaik. Oleh karena itu, penelitian ini bertujuan untuk menghasilkan sebuah sistem penunjam keputusan, dengan adanya sistem tersebut diharapkan kepala sekolah sebagai penilai pada SMK Putra Satria dapat terbantu dalam penilaian kinerja guru terbaik. Metode Simple Additive Weighting (SAW) digunkan untuk menentukan penilaian kinerja guru terbaik dengan menghasilkan perankingan alternatif dengan metode SAW. Berdasarkan uraian masalah diatas maka dari itu diperlukan membuat sistem penunjang keputusan agar dapat mempermudah SMK Putra Satria dalam menghasilkan perankingan untuk menentukan guru dengan kinerja terbaiknya setiap tahun dengan menggunakan metode Simple Additive Weighting (SAW), sehingga kepala sekolah dimudahkan untuk menentukan pilihan.
\end{abstract}

Kata kunci: Sistem Penunjang Keputusan, SAW, Penilaian Kinerja Guru, SMK Putra Satria

\section{PENDAHULUAN}

\subsection{Latar Belakang}

Dalam proses pembangunan dan keberhasilan Bangsa dan Negara, perlu dilakukannya proses pendidikan yang berkualitas yang merupakan suatu keharusan untuk setiap sekolah yang bertujuan untuk mencerdaskan generasi dan kehidupan Bangsa Indonesia agar dari proses pendidikan tersebut akan membentuk sosok individu yang berkualitas. Didunia pendidikan, guru, siswa, lingkungan pendidikan, kurikulum, sarana dan prasarana merupakan faktor penting dan berpengaruh yang dapat mempengaruhi keberhasilan dalam dunia pendidikan.dan proses kegiatan belajar mengajar .adalah guru. Karena guru sangat berpengaruh untuk menentukan siswa/siswi di masa yang akan datang untuk menjadikan siswa/siswi sebagai manusia yang berkualitas. adapun yang dimaksud guru adalah pendidik profesional yang berperan penting untuk memberikan arahan, bimbingan, mendidik agar menjadikan siswa/siswi yang cerdas dan berperilaku baik.

Sekolah Menengah Kejuruan (SMK) Putra Satria merupakan sekolah swasta di Jakarta Selatan yang berusaha untuk meningkatkan kualitas pendidikannya dengan meningkatkan kinerja guru agar dapat bersaing dengan Sekolah Menengah Kejuruan lainnya dengan cara memberikan apresiasi yaitu mengevaluasi kinerja guru di setiap tahunnya. Maka dari itu Sekolah Menengah Kejuruan (SMK) Putra Satria untuk guru yang berkinerja baik berhak mendapatkan penghargaan. Untuk menentukan kinerja guru terbaik, SMK Putra Satria selama ini pengambilan keputusan dengan cara menyebarkan kuesioner kepada siswa/siswi. Namun, pelaksanaan kurang berjalan dengan baik. Diantaranya, penyebaran kuesioner yang tidak terlaksana dengan baik, banyaknya responder yang lupa atau tidak mengembalikan kuesioner, belum terdapat metode dan membutuhkan waktu yang cukup lama untuk melakukan rekapitulasi.

Untuk menyelesaikan masalah tersebut dapat diatasi dengan membuat Sistem Penunjang Keputusan (SPK) yang berfungsi sebagai alat bantu bagi Kepala Sekolah untuk menentukan kinerja guru terbaik di Sekolah Menengah Kejuruan (SMK) Putra Satria.

Menurut Gorry dan Scott Morton (Abdullah et al., 2016) Sistem Penunjang Keputusan adalah Sistem berbasis computer interaktif, yang membantu para pengambil keputusan untuk menggunakan data dan berbagai model untuk memecahkan masalahmasalah tidak terstruktur [1].

Dalam Sistem Penunjang Keputusan (SPK) terdapat beberapa metode untuk mendukung 
pengambilan keputusan diantaranya adalah Simple Additive Weighting (SAW).

Berdasarkan uraian masalah diatas maka diperlukan untuk dibuatkan sistem penunjang keputusan agar dapat memudahkan dan mempercepat SMK Putra Satria dalam menentukan guru dengan kinerja terbaik dengan metode Simple Additive Weighting (SAW), sehingga kepala sekolah dimudahkan untuk menentukan pilihan [2].

\subsection{Studi Literatur}

Pada penilitian sebelumnya yang berkaitan dengan penentuan pemilihan kinerja guru terbaik dengan menggunakan metode Simple Additive Weighting (SAW) seperti yang dilakukan oleh [3] dalam jurnal Sistem Pendukung Keputusan Pemilihan Guru Terbaik Pada SMK Maria Goretti Pematangiantar menggunakan "Metode Simple Additive Weighting(SAW)" sebagai Sistem Pendukung Keputusan (Studi Kaus : SMK Maria Goretti Pematangiantar)”. SMK Maria Goretti Pematangsiantar, melakukan penelitian pada tanggal 25 november disetiap tahunnya saat berlangsungnya hari guru nasioanal. Dan untuk menentukan pemilihan guru di SMK Maria Goretti Pematangsiantar adalah Kepala Sekolah. Agar mengurangi kesalahan dalam menentukan pemilihan guru, dibutuhkan sebuat sistem agar dapat membantu dalam menentukan pemilihan dan dalam melakukan pemilihan tidak memerlukan waktu yang cukup lama. Tujuan penelitian ini adalah membangun sebuah aplikasi sistem penunjang keputusan yang dapat digunakan oleh pihak sekolah Maria Goretti untuk menganalisa seberapa besar pengaruh kinerja guru terhadap optimalisasi pengembangan pendidikan khsususnya dalam PBM (Proses Belajar Mengajar). Di SMK Maria Goretti, yang paling mempengaruhi pada proses optimalisasi sistem pendukung keputusan dengan menggunakan metode Simple Additive Weighting yaitu terdapat beberapa faktor pendukung diantaranya adalah 5 kriteria dan masing-masing kriteria tersebut terdapat bobot, yaitu: C1=Kedisiplinan:Sangat Baik dengan bobot 30\%, C2=Prakarsa:Baik dengan bobot 20\%, C3=Prestasi:Baik dengan bobot 20\%, C4=Tanggung Jawab:Cukup dengan bobot 15\%, C5=Menjaga Nama Baik:Cukup dengan bobot 15\%.

\section{METODE PENELITIAN}

\subsection{Metode Simple Additive Weighting} (SAW)

Simple Additive Weighting (SAW) merupakan metode penjumlahan terbobot. Konsep dasar metode SAW adalah mencari penjumlahan terbobot dari rating kinerja pada setiap alternatif pada semua kriteria (Kusumadewi, 2006) [4]. Metode SAW membutuhkan proses normalisasi matrik keputusan (X) ke suatu skala yang dapat diperbandingkan dengan semua rating alternatif yang ada. Terdapat dua atribut didalam metode simple additive weighting yaitu benefit atau keuntungan dan cost atau biaya [5]. Untuk menyelesaikan langkah tersebut dapat digunakan dengan cara sebagai berikut:

a. Menentukan alternative, yaitu adanya Ai.

b. Dijadikan acuan yang akan menentukan sebuah kriteria dalam pengambilan keputusan, yaitu Cj.

c. Memberikan nilai rating kecocokan setiap alternatif pada setiap kriteria.

d. Menentukan bobot preferentif atau tingkat kepentingan (W) setiap kriteria $\mathrm{W}=$ [W1,W2,W3,...,WJ]

e. Membuat tabel rating kecocokan dari setiap alternative pada setiap kriteria. Membuat matrik keputusan (X) yang dibentuk dari tabel rating kecocokan dari setiap alternative pada setiap kriteria. Nilai $\mathrm{X}$ setiap alternative (Ai) pada setiap kriteria (Cj) yang sudang ditentukan, dimana, $i=1,2, \ldots m$ dan $j=1,2, \ldots n$.

$$
x=\left[\begin{array}{lll}
x 11 & x 12 \cdots & x i j \\
\vdots & \ddots & \vdots \\
x 111 & x 12 \cdots & x i j
\end{array}\right]
$$

f. Menghitung nilai rating kinerja ternormalisasi (rij) dan alternatif Ai pada kriteria Cj dengan cara melakukan matrik normalisasi.

$$
r i j=\frac{x i j}{\operatorname{Max}\{x i j\}}
$$

Keterangan:

1. Kriteria keuntungan apabila nilai memberikan keuntungan bagi pengambilan keputusan, sebaliknya kriteria biaya apabila menimbulkan biaya bagi pengambil keputusan.

2. Apabila berupa kriteria keuntungan maka nilai dibagi dengan nilai dari setiap kolom, sedangkan untuk kriteria biaya nilai dari setiap kolom dibagi dengan nilai.

g. Hasil dari nilai rating kinerja ternormalisaso (rij) membentuk matrik ternormalisasi (R).

$$
R=\left[\begin{array}{lll}
x 11 & x 12 \cdots & x i j \\
\vdots & \ddots & \vdots \\
x 111 & x 12 \cdots & x i j
\end{array}\right]
$$

h. Hasil akhir nikai preferensi (Vi) diperoleh dari penjumlahan dari perkalian elemen baris matrik ternormalisasi (R) dengan bobot preferensi (W) yang bersesuaian elemen kolom matrik (W). Hasil perhitungan $\mathrm{Vi}$ yang lebih besar 
mengidindikasikan bahwa alternatif $\mathrm{Ai}$ merupakan alternatif terbaik.

$$
V i=\sum_{j=1}^{n} w j x r i j
$$

\subsection{Ketentuan Kriteria}

Berikut ini merupakan kriteria yang dibutuhkan untuk pengambilan keputusan penentuan guru terbaik pada Sekolah Menengah Kejuruan (SMK) Putra Satria.

Tabel 1. Ketentuan Kriteria

\begin{tabular}{ll}
\hline Kode Kriteria & Nama Kriteria \\
\hline KR01 & Absensi \\
KR02 & Kompetensi Pedagogik \\
KR03 & Kompetensi Kepribadian \\
KR04 & Kompetensi Sosial \\
KR05 & Kompetensi Profesional \\
\hline
\end{tabular}

Pada tabel 1, terdapat kode kroteria beserta nama kriteria yang terdiri dari KR01 untuk Absensi, KR02 unruk Kompetensi Pedagogik, KR03 untuk Kompetensi Kepribadian, KR04 Kompetensi Sosial, dan KR05 Kompetensi Profesional.

\subsection{Bobot Kriteria}

Berdasarkan data yang ada, berikut ini adalah bentuk dari hasil perhitungan bobot kriteria yang terdapat di SMK Putra Satria dan telah konsisten dan terdapat bobot yang ditetapkan disetiap kriteria yang telah ditentukan dan maksimal bobot 100\%.

Tabel 2. Bobot Kriteria

\begin{tabular}{|c|c|c|}
\hline Kode Kriteria & Nama Kriteria & Bobot \\
\hline KR01 & Absensi & $10 \%$ \\
\hline KR02 & Kompetensi Pedagogik & $10 \%$ \\
\hline KR03 & Kompetensi Kepribadian & $30 \%$ \\
\hline KR04 & Kompetensi Sosial & $20 \%$ \\
\hline KR05 & Kompetensi Profesional & $30 \%$ \\
\hline
\end{tabular}

Pada tabel 2, terdapat bobot perkriteria diantaranya, Absensi 10\%, Kompetensi Pedagogik 10\%, Kompetensi Kepribadian 30\%, Kompetensi Sosial 20\% dan Kompetensi Profesional 30\%.

\subsection{Bobot Kuesioner}

Berikut adalah data untuk mengkonfersi data nilai bobot Kuesioner.

Tabel 3. Bobot Kuesioner

\begin{tabular}{|c|c|}
\hline & 5 \\
\hline Baik Sekali & 4 \\
\hline Baik & 3 \\
\hline Cukup & 2 \\
\hline Kurang & 1 \\
\hline Kurang Sekali & \\
\hline
\end{tabular}

Pada tabel 3, terdapat data untuk mengkonfersi nilai bobot kuesioner yang terdiri dari Baik Sekali dengan point 5 , Baik dengan point 4 , Cukup dengan point 3, Kurang dengan point 2 dan Kurang Sekali dengan point 1 .

\subsection{Penggolongan Kriteria}

Berikut adalah data untuk penggolongan kriteria.

Tabel 4. Penggolongan Kriteria

\begin{tabular}{llll}
\hline No & Kriteria & Trend & \\
\cline { 3 - 3 } & & Benefit & Cost \\
\hline 1 & Absen & \\
2 & Kompetensi Pedagogik & \\
3 & Kompetensi Kepribadian & \\
4 & Kompetensi Sosial & \\
5 & Kompetensi Profesional & \\
\hline
\end{tabular}

Pada tabel 4, terdapat 1 cost yaitu absen, yang dimana semakin kecil kehadiran alfa nya rending semakin baik dan terdapat 4 benefit yaitu Kompetensi Pedagogik, Kepribadian, Sosial dan Profesional yang dimana apabila mendapatkan point tertinggi semakin bagus.

\section{HASIL DAN PEMBAHASAN}

3.1. Model Keputusan Dengan Simple Additive Weighting (SAW)

Dalam pemilihan penilaian kinerja guru terbaik pada SMK Putra Satria, berdasarkan banyaknya alternatif (guru) pada SMK Putra Satria, maka diambil 5 alternatif untuk dijadikan contoh dalam menentukan kinerja guru terbaik yang akan dinilai berdasarkan kriteria yang sudah ditetapkan, yaitu: 1) Absen, 2) Kompetensi Pedagogik, 3) Komperensi kepribadian, 4) Kompetensi Sosial, 5) Kompetensi profesional. Dimana data merupakan hasil rekapitulasi penilaian dari setiap kriteria.

a. Nilai alternatif persub kriteria

Berikut adalah nilai alternatif persub kriteria berdasarkan penilaian dari kuesioner.

Tabel 5. Nilai alternatif persub kriteria

\begin{tabular}{|c|c|c|c|c|c|c|}
\hline Kriteria & Sub Kriteria & \multicolumn{5}{|c|}{ Alternatif } \\
\cline { 2 - 7 } & & A1 & A2 & A3 & A4 & A5 \\
\hline Absensi & Sub 1 & 4 & 4 & 4 & 5 & 5 \\
\hline Pedagogik & Sub 2 & 5 & 5 & 5 & 3 & 3 \\
\cline { 2 - 7 } & Sub 3 & 5 & 4 & 4 & 4 & 3 \\
\cline { 2 - 7 } & Sub 4 & 4 & 4 & 3 & 4 & 3 \\
\hline Kepribadian & Sub 5 & 5 & 4 & 4 & 4 & 5 \\
\cline { 2 - 7 } & Sub 6 & 5 & 5 & 5 & 4 & 3 \\
\cline { 2 - 7 } & Sub 7 & 5 & 4 & 5 & 4 & 3 \\
\hline \multirow{3}{*}{ Sosial } & Sub 8 & 4 & 4 & 5 & 3 & 4 \\
\cline { 2 - 7 } & Sub 9 & 5 & 4 & 3 & 4 & 5 \\
\cline { 2 - 7 } & Sub 10 & 5 & 4 & 3 & 3 & 5 \\
\hline \multirow{2}{*}{ Profesional } & Sub 11 & 4 & 4 & 4 & 5 & 4 \\
\cline { 2 - 7 } & Sub 12 & 5 & 3 & 4 & 5 & 4 \\
\hline
\end{tabular}

Pada tabel 5, terdapat point-point yang diperoleh dari nilai kuesioner pada masing-masing alternatif. 
b. Nilai alternatif perkriteria

Berikut adalah nilai alternatif perkriteria dari bobot yang sudah ada sebelumnya dihitung untuk mendapatkan alternatif yang terbaik.

Tabel 6. Nilai alternatif perkriteria

\begin{tabular}{|c|c|c|c|c|c|}
\hline \multirow{2}{*}{ Alternatif } & \multicolumn{5}{|c|}{ Kriteria } \\
\cline { 2 - 6 } & Absensi & Pedagogik & Kepribadian & Sosial & Profesional \\
\hline A1 & 4 & 14 & 15 & 14 & 9 \\
\hline A2 & 4 & 13 & 13 & 12 & 7 \\
\hline A3 & 4 & 12 & 14 & 11 & 8 \\
\hline A4 & 5 & 11 & 12 & 10 & 10 \\
\hline A5 & 5 & 9 & 11 & 14 & 8 \\
\hline
\end{tabular}

Tabel 6, terdapat nilai alternatif dari masingmasing kriteria dan alternatif yang selanjutnya akan dilakukan perhitungan normalisasi.

c. Matriks normalisasi

Untuk menentukan nilai dari masing-masing alternatif dan kriteria berdasarkan benefit dan cost, dilakukan perhitungan normalisasi menjadi matriks dari masing-masing alternative, berikut perhitungannya:

1. Perhitungan Kriteria Absen

$$
\begin{gathered}
R 11=\min \\
R 21=\frac{\min (5,5,5,4,4)}{4}=\frac{4}{4}=1 \\
R 31=\frac{\min (5,5,5,4,4)}{4}=\frac{4}{4}=1 \\
R 11=\frac{\min (5,5,5,4,4)}{5}=\frac{5}{4}=1,25 \\
R 51=\frac{\min (5,5,5,4,4)}{5}=\frac{5}{4}=1,25
\end{gathered}
$$

\section{Perhitungan Kriteria Kompetensi Pedagogik}

$$
\begin{gathered}
R 12=\frac{14}{\max (14,13,12,11,9)}=\frac{14}{14}=1 \\
R 22=\frac{13}{\max (14,13,12,11,9)}=\frac{13}{14}=0,928571 \\
R 32=\frac{12}{\max (14,13,12,11,9)}=\frac{12}{14}=0,857143 \\
R 42=\frac{11}{\max (14,13,12,11,9)}=\frac{11}{14}=0,785714 \\
R 52=\frac{9}{\max (14,13,12,11,9)}=\frac{9}{14}=0,642857
\end{gathered}
$$

\section{Perhitungan Kriteria Kompetensi} Kepribadian

$R 13=\frac{14}{\max (14,13,12,11,9)}=\frac{14}{14}=1$

$$
\begin{aligned}
& R 23=\frac{13}{\max (15,13,14,12,11)}=\frac{13}{15}=0,86667 \\
& R 33=\frac{14}{\max (15,13,14,12,11)}=\frac{14}{15}=0,93333
\end{aligned}
$$

$$
R 43=\frac{12}{\max (15,13,14,12,11)}=\frac{12}{15}=0,8
$$

$R 53=\frac{11}{\max (15,13,14,12,11)}=\frac{11}{15}=0,73333$

4. Perhitungan Kriteria Kompetensi Sosial

$$
R 14=\frac{14}{\max (14,12,11,10,14)}=\frac{14}{14}=1
$$

$$
R 24=\frac{12}{\max (14,12,11,10,14)}=\frac{12}{14}=0,857143
$$

$$
R 34=\frac{11}{\max (14,12,11,10,14)}=\frac{11}{14}=0,785714
$$

$R 44=\frac{10}{\max (14,12,11,10,14)}=\frac{10}{14}=0,714285$

$$
R 54=\frac{14}{\max (14,12,11,10,14)}=\frac{14}{14}=1
$$

5. Perhitungan Kompetensi Profesional

$$
\begin{aligned}
& R 15=\frac{9}{\max (9,7,8,10,8)}=\frac{9}{10}=0,9 \\
& R 25=\frac{7}{\max (9,7,8,10,8)}=\frac{7}{10}=0,7 \\
& R 35=\frac{8}{\max (9,7,8,10,8)}=\frac{8}{10}=0,8 \\
& R 45=\frac{10}{\max (9,7,8,10,8)}=\frac{10}{10}=1 \\
& R 55=\frac{8}{\max (9,7,8,10,8)}=\frac{8}{10}=0,8
\end{aligned}
$$

d. Hasil nilai normalisasi

Kemudian dari bobot yang sudah ada akan dihitung untuk mendapatkan nilai tertinggi agar 
dapat menentukan perankingan dan alternatif terbaik.

Tabel 7. Hasil Nilai Normalisasi

\begin{tabular}{|c|c|c|c|c|c|}
\hline Altematif & Absensi & $\begin{array}{c}\text { Kompetensi } \\
\text { Pedagogik }\end{array}$ & $\begin{array}{c}\text { Kompetensi } \\
\text { Kepribadian }\end{array}$ & $\begin{array}{c}\text { Kompetensi } \\
\text { Sosial }\end{array}$ & $\begin{array}{c}\text { Kompetensi } \\
\text { Profesional }\end{array}$ \\
\hline $\mathrm{A} 1$ & 1 & 1 & 1 & 1 & 0,9 \\
\hline $\mathrm{A} 2$ & 1 & 0,928571 & 0,86667 & 0,857143 & 0,7 \\
\hline $\mathrm{A} 3$ & 1 & 0,857143 & 0,93333 & 0,785714 & 0,8 \\
\hline $\mathrm{A} 4$ & 1,25 & 0,785714 & 0,8 & 0,714285 & 1 \\
\hline $\mathrm{A} 5$ & 1,25 & 0,642857 & 0,73333 & 1 & 0,8 \\
\hline Bobot & 0,1 & 0,1 & 0,3 & 0,2 & 0,3 \\
\hline
\end{tabular}

Pada tabel 7, terdapat hasil nilai normalisasi yang akan dihitung sebagai berikut:

1) Muthiah Zulfa (A1)

$=\{(0,1 \times 1)+(0,1 \times 1)+(0,3 \times 1)+(0,2 \times 1)+(0,3 \times 0,9)\}$

$=(0,1+0,1+0,3+0,2+0,27)$

$=0,97$

2) Eka Rimatuzzariah (A2)

$=\{(0,1 \times 1)+(0,1 \times 0,928571)+(0,3 \times 0,86667)+$

$(0,2 \times 0,857143)+(0,3 \times 0,7)\}$

$=(0,1+0,0928571+0,260001+0,1714286+0,21)$

$=0,8342867$

3) Intan Rizki Permata Sari (A3)

$=\{(0,1 \times 1)+(0,1 \times 0,857143)+(0,3 \times 0,93333)+$

$(0,2 \times 0,785714)+(0,3 \times 0,8)\}$

$=(0,1+0,0857143+0,279999+0,1571428+0,24)$

$=0,8628561$

4) Novianto Sulistyo Putro (A4)

$=\{(0,1 \times 1,25)+(0,1 \times 0,785714)+(0,3 \times 0,8)+$

$(0,2 \times 0,714285)+(0,3 \times 1)\}$

$=(0,125+0,0785714+0,24+0,142857+0,3)$

$=0,8864284$

5) Fadia Hayati (A5)

$=\{(0,1 \times 1,25+(0,1 \times 0,642857)+(0,3 \times 0,73333)+$

$(0,2 \times 1)+(0,3 \times 0,8)\}$

$=(0,125+0,0642857+0,219999+0,2+0,24)$

$=0,84928477$

e. Hasil Penelitian

Berikut adalah hasil perankingan yang diperoleh dari hasil perhitungan:

Ranking 1 : Muthiah Zulfa

Ranking 2 : Novianto Sulistyo Putro

Ranking 3 : Intan Rizki Permata Sari

Ranking 4 : Fadla Hayati

Ranking 5 : Eka Rimatuzzariah

Sehingga dapat disimpulkan bahwa nilai terbesar diperoleh oleh Muthiah Zulfa sebagai alternatif terbaik dengan nilai $\mathbf{0 , 9 7 . ~}$

\subsection{Proses Bisnis}

Pada sistem usulan penilaian kinerja guru terbaik pada SMK Putra Satria, dimulai dengan login lalu pengentrian data guru oleh wakil kepala sekolah bidang kurikulum, setelah itu wakil kepala sekolah bidang kurikulum melakukan entri absensi, entri kriteria, entri subkriteria, entri nilai alternatif persubkriteria, kemudian memilih kandidat lalu melakukan perhitungan nilai alternatif yang selanjutnya dihitung menggunakan matriks normalisasi. Hasil perhitungan tersebut diurutkan atau dirankingkan sehingga didapatkan alternatif terbaik yang kemudian wakil kepala sekolah bidang kurikulum menyerahkan laporan ke kepala sekolah kemudian kepala sekolah menerima laporan tersebut untuk evaluasi kinerja guru terbaik SMK Putra Satria.

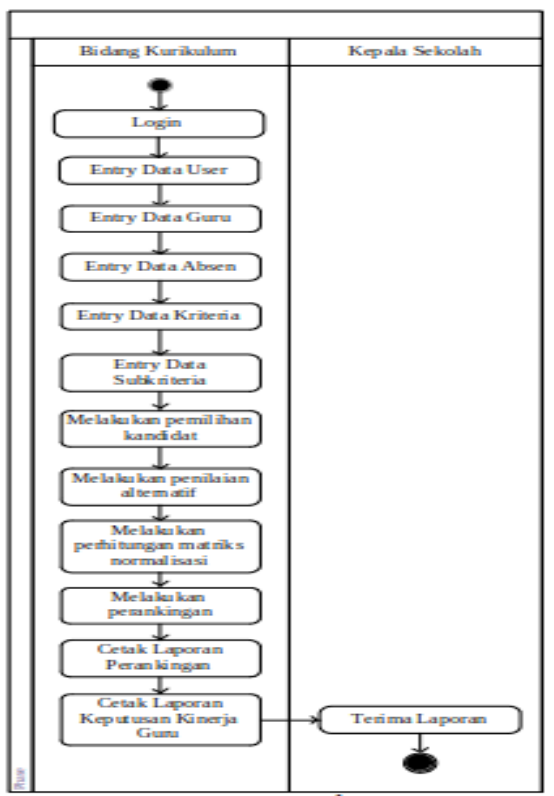

Gambar 1. Activity Diagram usulan

\subsection{Perancangan Sistem}

Berikut ini disajikan tiga use case diagram yaitu use case diagram entri, use case diagram proses, dan use case diagram laporan.

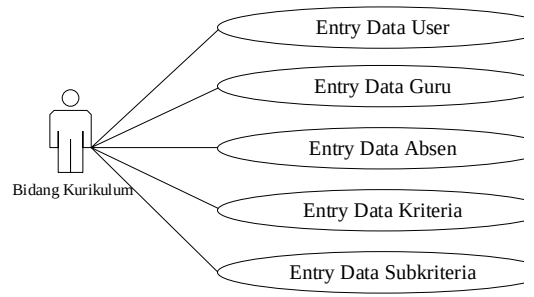

Pada gambar 2, terdapat use case diagram entri yang terdiri dari Entry Data User, Entry Data Guru, 
Entry Data Absen, Entry Data Kriteria dan Entry Data Subkriteria.

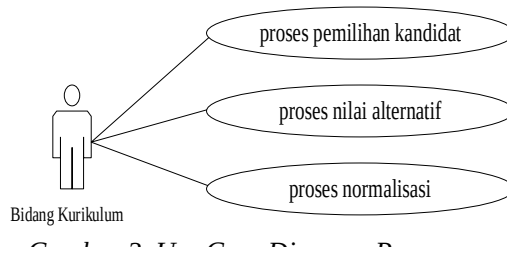

Pada gambar 3, terdapat Use Case Diagram Proses yang terdiri dari proses pemilihan kandidat, proses nilai alternative, proses normalisasi.

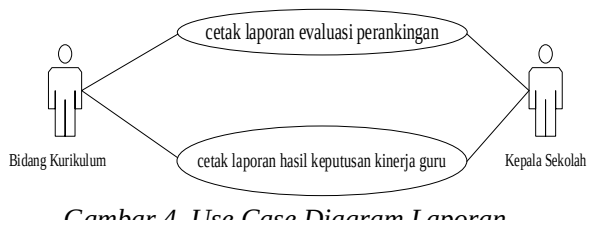

Pada gambar 4, terdapat Use Case Diagram Laporan yang terdiri dari cetak laporan evaluasi perankingan dan cetak laporan hasil keputusan kinerja guru.

\subsection{Hasil Tampilan}

a. Menu Utama

Terdapat menu utama yang terdiri dari Data master, Analisa, Absensi, Laporan, Control user dan logout.

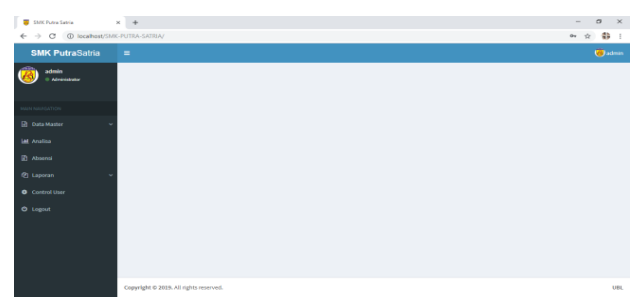

Gambar 5. Layar Menu Utama

Pada gambar 5, Ketika sistem dijalankan, maka akan muncul menu utama yang terdiri dari Data Master, Analisa, Absensi, Laporan, Control User, Logout.

b. Entry Data Guru

Entry data guru merupakan bagian dari data master. Data master tersebut berisikan guru, kriteria dan sub kriteria.

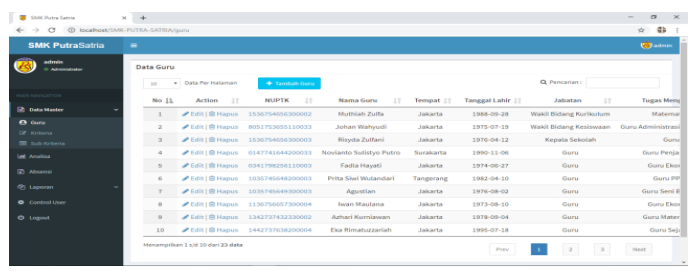

Gambar 6. Layar Form Data Guru
Pada gambar 6, Ketika user memilih menu Data Master lalu memilih entry data guru maka akan muncul muncul form entry data guru yang ada pada SMK Putra Satria, jika sudah lengkap lalu klik tombol simpan untuk menyimpan data ke dalam database pada tabel data Guru, , jika ingin mengubah data yang sudah ada caranya adalah klik edit pada data yang ingin diubah, lalu ubah data dan klik button update data untuk menyimpan data terbaru, Jika ingin menghapus data guru klik button hapus pada data yang ingin dihapus, lalu hapus data dan klik button YA, Jika pada saat melakukan penginputan data kemudian tidak jadi maka user dapat klik tombol tutup dan otomatis form untuk mengisi data guru tertutup .

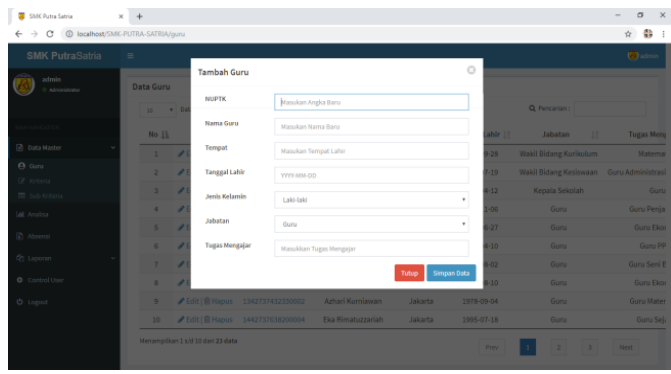

Gambar 7. Layar Form Entri Data Guru

Pada gambar 7, ketika user ingin melakukan tambah data pada guru, user dapat memasukan data ditampilan form data guru setelah klik button update data untuk menyimpan data terbaru.

c. Proses Pemilihan Kandidat

Pemilihan kandidat merupakan inputan data kandidat guru yang sudah disetujui sebagai kandidat.

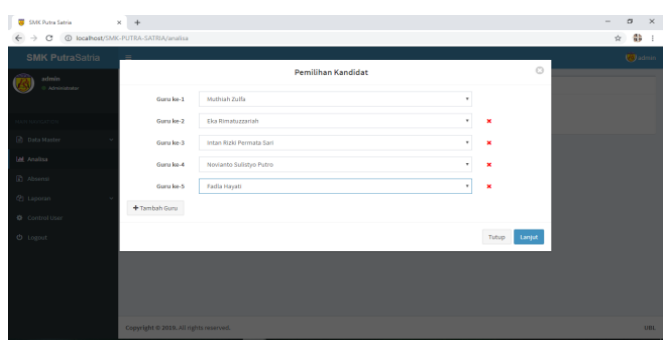

Gambar 8. Layar Proses Pemilihan Kandidat

Pada gambar 8, user pilih kandidat beberapa guru yang akan dinilai, Jika user sudah memilih beberapa kandidat guru untuk bisa mengentry nilainilai alternatif dari masing-masing guru.

d. Cetak Laporan Evaluasi Perankingan

Cetak laporan evaluasi perankingan menggambarkan kegiatan hasil user melakukan kegiatan cetak laporan rekap evaluasi yang menghasilkan perankingan. 


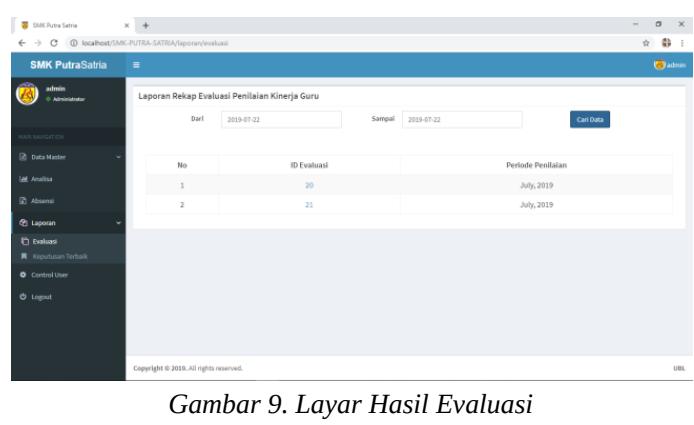

Pada gambar 9, Ketika user klik menu Evaluasi, dan memasukan tanggal periode penilaian maka akan muncul data laporan rekap evaluasi hasil penilaian sesuai perhitungan.

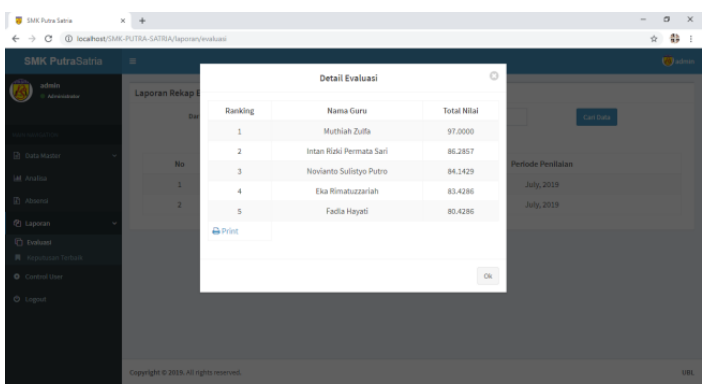

Gambar 10. Layar Cetak Hasil Detail Evaluasi

Pada gambar 10, ketika user mengklik ID_evaluasi maka akan muncul detail evaluasi berupa perankingan, jika user ingin mengetahui dan cetak perankingan maka user mengklik tombol print

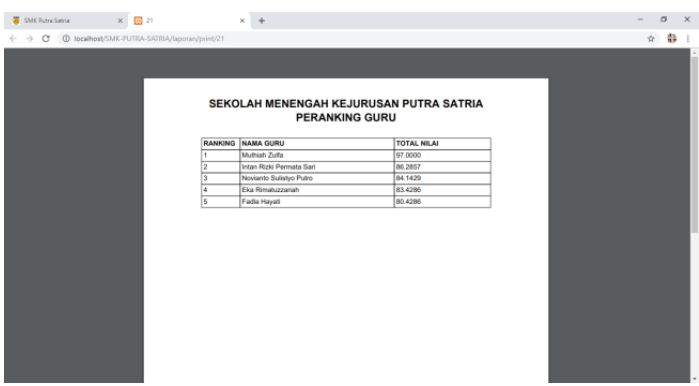

Gambar 11. Layar Cetak Laporan Hasil Evaluasi Perankingan

Pada gambar 11, terdapat hasil keluaran dari perankingan yang sudah dilakukan print.

e. Cetak Laporan Hasil Keputusan Kinerja Guru

Cetak laporan hasil keputusan kinerja guru ini menggambarkan hasil keputusan guru terbaik, dan user melakukan kegiatan cetak laporan hasil keputusan.

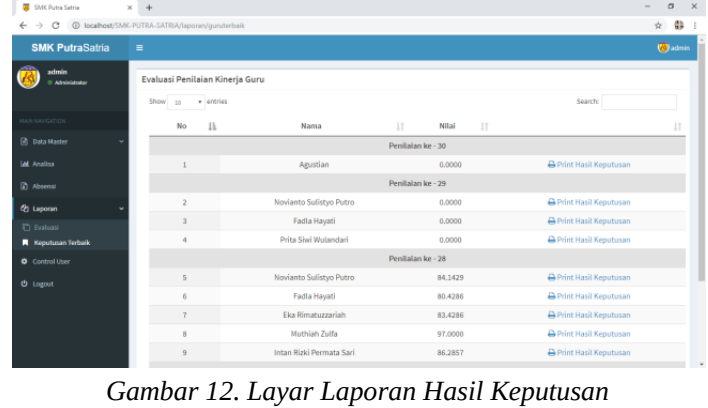

Pada gambar 12, ketika user memilih menu Laporan lalu akan tampil laporan keputusan terbaik, lalu user mencari data guru untuk dengan memasukan nip di pencarian. Jika user menyetujui guru tersebut menjadi guru terbaik maka user bisa print yang sudah disetujui.

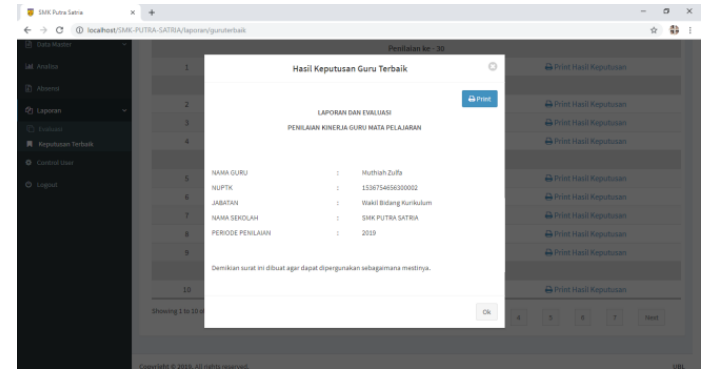

Gambar 13. Layar Cetak Laporan Hasil Keputusan Penilaian Kinerja Guru Terbaik

Pada gambar 13, terdapat form untuk melakukan print pada data yang sudah disetujui. Jika user menyetujui guru tersebut menjadi guru terbaik maka user bisa print laporan, apabila user tidak setuju dan memilih guru lain dari deretan 5 guru terbaik maka user bisa memilih salah satu radio button tersebut dengan mengklik button print. seperti pada Jika ingin keluar dari form, user dapat mengklik tombol silang.

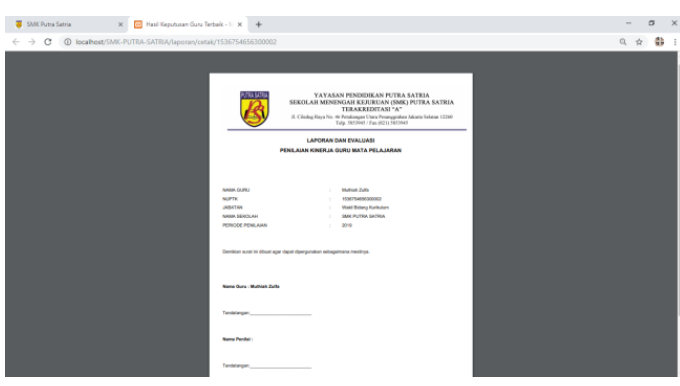

Gambar 14. Layar Cetak Laporan Hasil Keputusan Penilaian Kinerja Guru Terbaik

Pada gambar 14, terdapat hasil keluaran dari cetak laporan untuk hasil keputusan penilaian kinerja guru terbaik yang selanjutnya akan diberikan kepada guru 


\section{KESIMPULAN}

Berdasarkan penelitian yang telah dilakukan pada SMK Putra Satria, terdapat kesimpulan sebagai berikut :

a. Diharapkan Sistem Penunjang Keputusan ini dapat mempermudah Kepala Sekolah dalam pengolahan data penilaian kinerja guru.

b. Dengan dibuatkan sistem diharapkan proses penginputan data menjadi mudah dan lebih teliti.

c. Berdasarkan kriteria Absen dengan bobot $10 \%$, Pedagogik dengan bobot $10 \%$, Kepribadian dengan bobot 30\%, Sosial dengan bobot 20\%, dan Profesional dengan bobot $30 \%$.

d. Berdasarkan hasil studi kasus dalam penentuan penilaian guru terbaik pada SMK Putra Satria didapatkan hasil bahwa guru yang bernama Muthiah Zulfa dengan nilai 0,97 .

\section{DAFTAR PUSTAKA}

[1] Irawan, D. and Mafrudhoh, N. 'Analisis Sistem Pendukung Keputusan untuk Pemberian Keputusan Pembebasan Biaya Bagi Siswa yang Kurang Mampu Menggunakan Metode Simple Additive Weighting (Study Kasus MI Hidayatuul Mubtadiin Srikaton Adiluwih)', Jurnal TAM (Technology Acceptance Model), 7, 2016 , pp. 27-37.

[2] Muslihudin, M. et al. 'Guru Dengan Menggunakan Metode Simple Additive Weighting ( Saw ) Pada Smk', 2(2302-3805), 2017, pp. 318-326.

[3] Utara-indonesia, S. '2 , 3 , 4', Sistem Pendukung Keputusan Pemilihan Guru Terbaik Pada SMK Maria Goretti Pematangsiantar Dengan Menggunakan Metode Simple Additive Weighting (SAW), 1(2527-5771), 2016, p. 63.

[4] Masalah, L. B. 'Sistem Pendukung Keputusan Penilaian Kinerja Guru Menggunakan Metode SAW ( Simple Additive Weighting ) Pada SMA N 01 Sidorejo Yuna Ningsih Jurusan Sistem Informasi STMIK Pringsewu Lampung Jl . Wisma Rini No . 09 pringsewu Lampung’. (no date)

[5] Kurniawan, A. 'Analisis Dan Perancangan Sistem Pendukung Keputusan Penilaian Kinerja Guru (PKG) Menggunakan Metode Simple Additive Weighting (SAW) Pada SD Negeri 1 Wonoroto', 2016, pp. 6-7. 